\title{
Reflexões sobre a formação de docentes da e para a Educação Infantil
}

\begin{abstract}
Resumo: Neste artigo, analisa-se a formação inicial das professoras ${ }^{1}$ da Educação Infantil, utilizando-se estatísticas sobre escolaridade, características dos cursos que as formam e resultados de estudos recentes sobre o lugar da educação infantil nas matrizes curriculares de cursos de Pedagogia, os quais, em consonância com as Diretrizes Curriculares Nacionais para o Curso de Graduação em Pedagogia, licenciatura, Resolução CNE/CP nº 01/2006, são responsáveis pela formação em nível superior dessas profissionais. São também apontados aspectos que, na visão das autoras, devem constar na formação inicial de professoras de maneira a contribuir para a qualidade da Educação Infantil ofertada no País. Considerando os problemas identificados em estudos que analisam os impactos da Resolução CNE/CP n n 01/2006, os quais constatam dispersão, fragmentação e superficialidade do objeto do curso de Pedagogia, apresenta-se, como convite ao debate, uma proposta de matriz curricular fictícia para uma suposta licenciatura, que seria exclusiva para a formação de professoras da educação infantil. Cientes de que não existe, nos cursos de Pedagogia de universidades públicas brasileiras, uma licenciatura específica para Educação Infantil, o artigo apresenta essa possibilidade como um convite à reflexão. A matriz foi elaborada tendo como pretensão a formação de professoras capacitadas para cuidar e educar crianças em creches e pré-escolas, de acordo com as Diretrizes Curriculares Nacionais para a Educação Infantil.
\end{abstract}

Palavras-chave: Formação de professores. Curso de Pedagogia. Currículo. Educação Infantil.

\section{Considerações iniciais}

Atualmente, no Brasil, parte expressiva das professoras da Educação Infantil possui nível superior de escolaridade. Segundo o Censo Escolar de 2017 (BRASIL, 2017a), dos 557 mil docentes em exercício nesta etapa, quase 68\% graduaram-se em licenciatura. Se desagregarmos os dados, considerando os dois segmentos, creche e pré-escola, os percentuais se mantêm semelhantes: 65\% das professoras que atuam em creches e 69\% das que atuam em pré-escolas possuem alguma licenciatura. A comparação, com os dados da década anterior, evidencia a progressiva melhora nesse indicador. Em 2007 (BRASIL, 2008), 37\% das 95.643 professoras das creches haviam concluído alguma licenciatura, percentual que, para as que atuavam na pré-escola, atingia 45\% do total de 240.543 docentes.
Mônica Correia Baptista Universidade Federal de Minas Gerais (UFMG)

monicacb.ufmg@gmail.com

Ângela Rabelo Barreto

Consultora e pesquisadora na área da Educação Infantil.

Aposentada do Instituto de Pesquisa Econômica Aplicada (Ipea) amrfbarreto@uol.com.br

(1) Ao nos referirmos às profissionais que exercem a docência na Educação Infantil, utilizaremos o genérico feminino, em consideração ao fato de essa profissão ser exercida, na sua grande maioria, por mulheres, ainda que estejamos cientes de que haja homens atuando nessa profissão e ainda que esperemos que seja crescente essa participação, o que certamente, trará os benefícios que a diversidade proporciona. Do mesmo modo, usaremos o genérico feminino ao nos referirmos ao segmento de estudantes da Pedagogia, com as mesmas ressalvas apontadas em relação às profissionais. 
Ainda que essa seja uma notícia alvissareira, o aumento no nível de escolaridade e habilitação para a docência, por si só, não é a garantia de que a ele tenha correspondido uma melhoria na atuação profissional com impacto na qualidade educacional para crianças de zero a seis anos incompletos. Para que a formação em nível superior cumpra adequadamente seu papel de preparar profissionais para a docência na Educação Infantil, é preciso que os cursos de Pedagogia e Normal Superior, responsáveis legalmente pela formação inicial das professoras da Educação Infantil e anos iniciais do Ensino Fundamental, considerem, em seus currículos, as especificidades da primeira infância. Nesse sentido, esses cursos precisam reconhecer, de um lado, que os eixos do processo educativo são os sujeitos para os quais a Educação Infantil se destina e, de outro lado, as particularidades que caracterizam a faixa etária que integra a primeira etapa da Educação Básica. Em outras palavras, um currículo comprometido com uma Educação Infantil de qualidade precisa tomar as crianças e sua peculiar forma de aprender e de se desenvolver como referências para a organização dos tempos e espaços educativos. Ao se conceber as crianças de zero a seis anos e sua maneira de aprender e de se relacionar com o mundo, os eixos norteadores para as propostas curriculares, superase a tradicional organização pautada em conteúdos acadêmicos, em disciplinas ou em áreas de conhecimento. A organização escolar, referenciada nos sujeitos e nas características próprias do ciclo de idade de formação, fomenta práticas educativas comprometidas com a ampliação das experiências infantis, nas mais diversas áreas do conhecimento e da vivência humana.

Essa maneira de conceber a Educação Infantil remete ao papel das professoras e, mais especificamente, à sua formação. Algumas perguntas podem ajudar a compreender a situação atual e a encontrar caminhos para a superação dos desafios, tais como: a formação docente, da forma como vem sendo oferecida, tem contribuído para a construção de uma Educação Infantil de qualidade? Que saberes e conhecimentos devem ser assegurados às professoras para que possam apoiar a construção de conhecimentos e para que sejam capazes de organizar o processo educativo de maneira a ampliar as experiências dos bebês e das demais crianças pequenas, nas diferentes dimensões da vida humana? Como deveria se estruturar a formação docente comprometida com a 
construção de uma Educação Infantil centrada nas crianças e na sua forma de apropriar-se do mundo?

Neste artigo, examinaremos dados sobre a oferta dos cursos de Pedagogia, no Brasil. Em seguida, buscaremos refletir sobre aspectos que caracterizam a oferta do curso da Faculdade de Educação da Universidade Federal de Minas Gerais (FaE/UFMG), na qual atuamos. O objetivo do artigo é, pois, o de incitar reflexões sobre a formação de professoras da Educação Infantil, examinando dados sobre a formação inicial dessas profissionais e discutindo aspectos presentes na proposta curricular de uma dada realidade. Finalmente, pretende-se, por meio da apresentação de uma matriz curricular fictícia para um curso superior pretensamente destinado exclusivamente à formação de professoras da Educação Infantil, estabelecer um convite ao debate e estimular possíveis construções coletivas e solidárias. A metodologia utilizada inclui, portanto, análise de dados estatísticos, de documentos oficiais, incluindo matrizes curriculares, e de publicações recentes sobre o tema, e em diálogo com essas análises, a construção de uma proposta para debate.

\section{A Educação Infantil no curso de Pedagogia}

Segundo a legislação brasileira, ainda que se admita o exercício profissional para egressos do curso de magistério de nível médio, a formação inicial para atuar como docente da Educação Infantil deve se dar no curso de Pedagogia ou Normal Superior. (BRASIL, 1996,2013, 2017c) Se, como vimos acima, a maioria das professoras que atuam na Educação Infantil possuem nível superior de escolaridade, é forçoso indagar: onde são formadas as professoras da Educação Infantil? Como a Educação Infantil está contemplada nos cursos de formação de nível superior?

O último Censo da Educação Superior (BRASIL, 2017b) revela que aproximadamente 126 mil alunas concluíram o curso de Pedagogia, em 2016, consideradas as modalidades presencial e a distância, das instituições públicas e privadas (Figura 1). 
Figura 1. Brasil. Concluintes do curso de Pedagogia, 2016, segundo categoria administrativa e modalidade, presencial ou a distância.

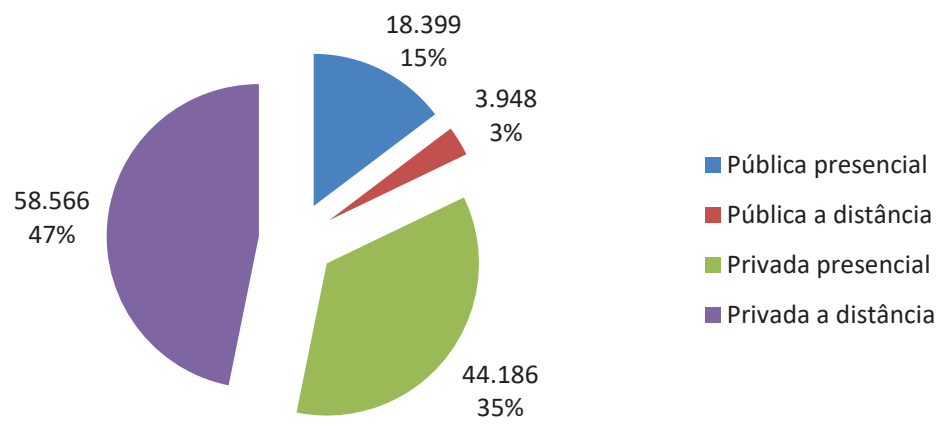

Fonte: elaboração das autoras a partir de dados do INEP/Censo da Educação Superior (2017b).

Mais de $80 \%$ dessas conclusões ocorreram em instituições privadas, nas quais predomina a modalidade a distância (EAD). Somam quase $47 \%$ as alunas que realizaram seus estudos a distância em instituições privadas. As instituições públicas de ensino superior formaram apenas 18\% das pessoas que concluíram o curso de Pedagogia, no País, naquele ano, sendo 15\% na modalidade presencial e 3\% em EAD.

Comparando-se os números de concluintes de Pedagogia em 2016 aos de 2009 (Figura 2), observa-se que nesses últimos anos houve crescimento expressivo (na casa dos 40\%) nos cursos presenciais, nas duas instâncias, pública e privada. Houve aumento nas conclusões, na modalidade a distância em instituições privadas, porém de menor monta (7\%), ao tempo em que essas decresceram na instância pública.

Figura 2. Brasil: Concluintes do Curso de Pedagogia - 2009 e 2016

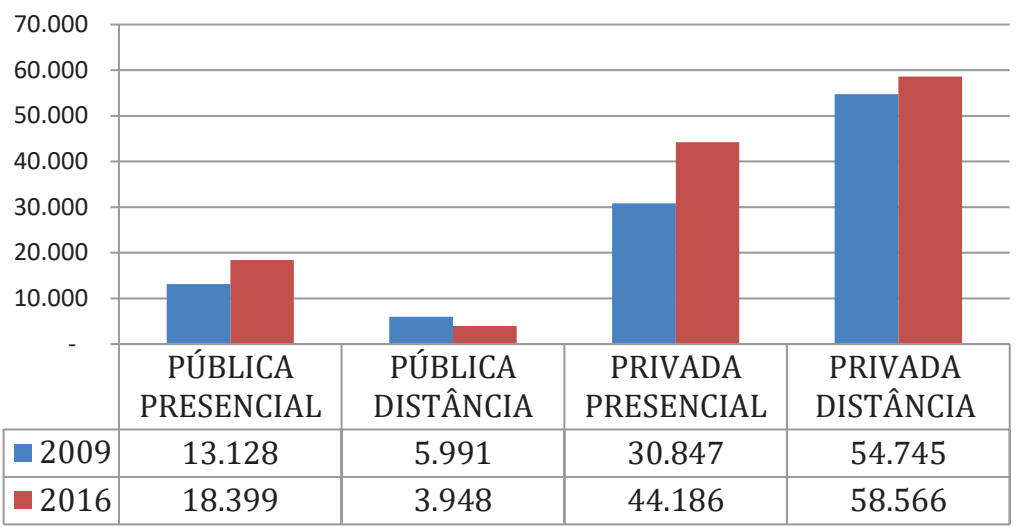

Fonte: elaboração das autoras a partir de dados do INEP/Censo da Educação Superior (2010, 2017b). 
Em sete anos (Figura 3), as participações das esferas pública e privada nas conclusões em Pedagogia não se alteraram (cerca de $18 \%$ e $82 \%$ ). Por outro lado, com relação à modalidade, a EAD mostrou uma redução de 58\% para 50\% neste período. Ainda que tenha havido tal diminuição, os cursos privados a distância representam quase metade das conclusões do curso de Pedagogia. A propósito, cabe mencionar que esse curso concentra o maior percentual do alunado da graduação a distância no País.

Figura 3. Brasil. Concluintes do curso de Pedagogia, 2009 e 2016, segundo categoria administrativa e modalidade, presencial ou a distância

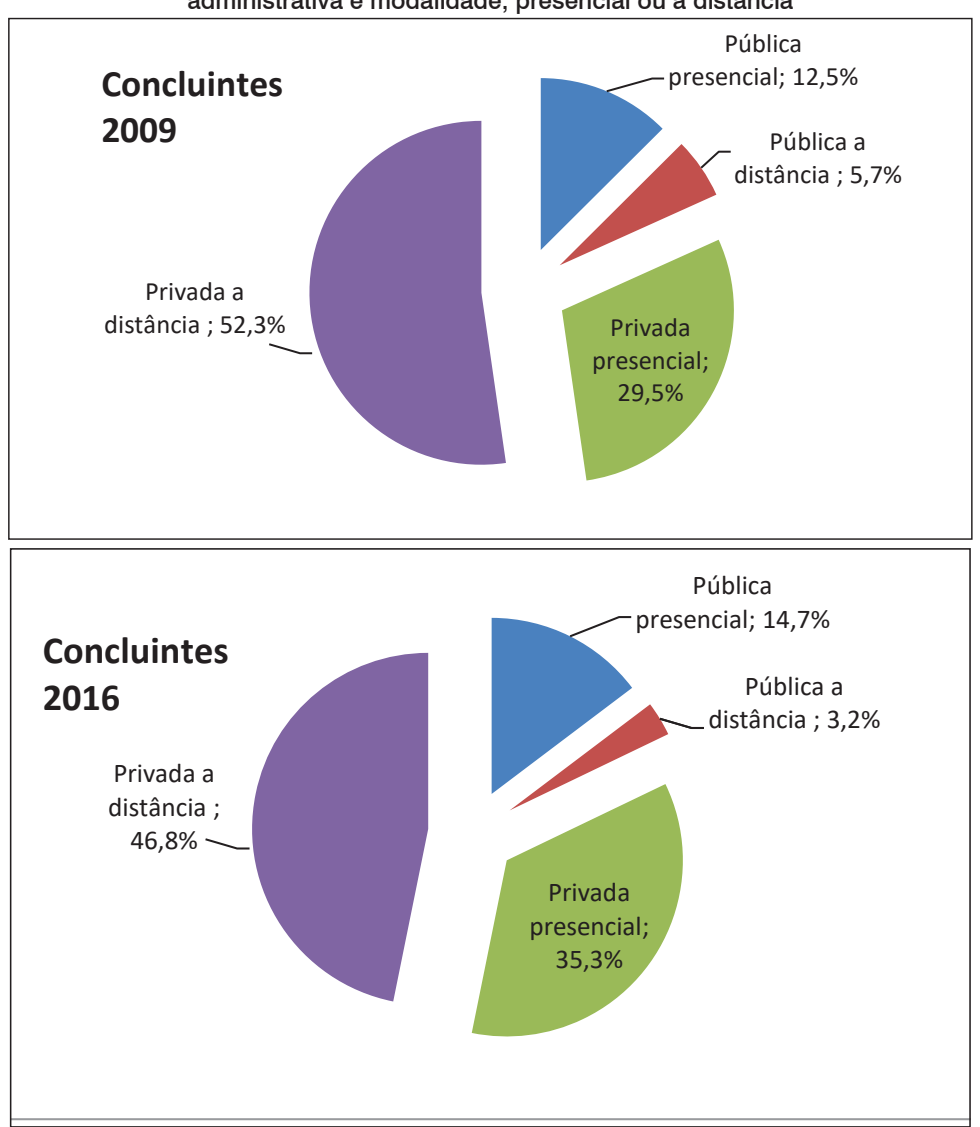

Fonte: elaboração das autoras a partir de dados do INEP/Censo da Educação Superior (2010, 2017b).

Considerando que mais de $80 \%$ das pessoas concluintes do curso de Pedagogia são formadas em instituições privadas, as quais, excepcionalmente, desenvolvem pesquisa ou investem na produção de conhecimentos, como se espera das instituições de ensino superior (BARRETTO, 2015), e, finalmente, que quase a metade das pessoas concluem seus cursos na modalidade EAD, 
nos quais predomina, como assevera Scheibe (2006, p. 199), "uma concepção apenas técnica da sua formação, sem contemplar o preparo necessário para que esses profissionais possam lidar com a complexidade dos determinantes escolares e pedagógicos", podemos deduzir que a formação de professoras para atuar na Educação Infantil tem ocorrido prioritariamente em contextos aquém dos desejáveis, com escassos investimentos em pesquisas, fator essencial para apoiar as necessárias mudanças que devem ser operadas nessa formação. Esses aspectos denotam a ausência de uma política pública efetiva e consistente de formação comprometida com a qualidade da Educação Básica.

A segunda pergunta indispensável refere-se a como a Educação Infantil está contemplada nos cursos de Pedagogia? Ainda que esta seja uma questão que mereça aprofundamento, alguns estudos sobre esse tema vêm sendo realizados, os quais abrangeram diferentes amostras. Dentre esses estudos podemos destacar a pesquisa coordenada por Gatti (GATTI, 2010; GATTI; BARRETTO, 2009) sobre a formação de professore(a)s para a Educação Básica, no Brasil.

Nessa pesquisa foi estudada uma amostra de matrizes curriculares de cursos de licenciatura, dentre os quais, o curso de Pedagogia. Para as análises, tomaram-se como referência ementas de disciplinas de 71 cursos presenciais em Pedagogia, levantados a partir do Censo da Educação Superior de 2006, e distribuídos em todo o País. Concluiu-se que os currículos eram fragmentados, isto é, compostos por um conjunto disciplinar bastante disperso. Segundo as autoras, as horas dedicadas às disciplinas de formação profissional representavam pequena proporção do curso, e as abordagens geralmente eram descritivas e não relacionavam adequadamente teoria e prática. A pesquisa buscou ainda verificar o quanto cada etapa e modalidade da Educação Básica estaria contemplada nos currículos de Pedagogia analisados. Constatouse que eram poucos os cursos que propunham disciplinas que permitissem, às alunas, maior aprofundamento em relação à Educação Infantil, representando apenas 5,3\% do total das disciplinas identificadas no estudo.

Em artigo publicado mais recentemente, os pesquisadores Pimenta, Fusari, Pedroso e Pinto (2017) relatam estudo sobre as matrizes curriculares de 144 cursos de Pedagogia, de instituições públicas e privadas do estado de São Paulo, levantadas nos anos de 2012 e 2013. Esses autores tinham como objetivo discutir a formação 
de professores "polivantes"1 para a Educação Infantil e para os anos iniciais do ensino fundamental, oferecida nos cursos de Pedagogia, organizados a partir das Diretrizes Curriculares Nacionais do Curso de Graduação em Pedagogia, licenciatura, de 2006. (BRASIL, 2006) Os dados encontrados pelos pesquisadores revelam que 86\% dos cursos são oferecidos por instituições privadas, e, como esperado e confirmado no estudo, possuem carga horária mínima e não têm a pesquisa como inerente à formação.

No mesmo artigo, Pimenta, Fusari, Pedroso e Pinto (2017) observaram, nas matrizes curriculares da Pedagogia, maior presença de disciplinas dedicadas ao ensino fundamental e um percentual menor daquelas, referentes à Educação Infantil. Essas últimas representavam apenas $9,13 \%$ do total de disciplinas levantadas no estudo. Na análise interpretativa dos resultados, os autores concluem que

[...] esses cursos, em sua maioria, não estão formando o pedagogo e, tampouco, um professor polivalente para a educação infantil e anos iniciais do ensino fundamental, pois sua formação se mostra frágil, superficial, generalizante, fragmentada, dispersiva e sem foco. (PIMENTA FUSARI, PEDROSO; PINTO, 2017, p. 15)
(1) Pimenta,Fusari, Pedroso e Pinto (2017, p. 17) definem a expressão "professor polivalente" como sendo o professor responsável por ensinar as disciplinas (matérias) básicas dos anos iniciais do Ensino Fundamental: língua portuguesa (alfabetização), história, geografia, ciências e matemática. Esclarecem que, apesar de essa denominação não mais aparecer na legislação brasileira, permanece a finalidade de formar esses professores, que continuam atuando como polivalentes.

O lugar reduzido da Educação Infantil na graduação em Pedagogia, percebido nesses estudos de Gatti e Barretto (2009) e Pimenta, Fusari, Pedroso e Pinto (2017) pode ter como explicação o fato de ser essa uma área ainda "recente" no sistema educacional, tanto como etapa educativa quanto como objeto de investigação.

As conclusões a que chega Albuquerque (2013), a partir dos dados de sua pesquisa de doutorado, apresentam certa discrepância em relação aos estudos assinalados acima. Na sua pesquisa, Albuquerque (2013) buscou, nos anos 2010-2011, conhecer as configurações curriculares do curso de Pedagogia, voltadas para a formação de professoras da Educação Infantil. Foram investigados 33 cursos, nesse caso, todos ofertados por universidades federais. A pesquisadora pretendeu analisar, entre outros objetivos, a forma como estariam sendo consideradas as especificidades das crianças e da infância, nesses cursos, estabelecendo comparações entre a distribuição de carga horária, o período em que eram ofertadas e os temas e conteúdos contemplados nas ementas das disciplinas.

Dentre as conclusões a que chega a autora, destacamos a que refuta a tese segundo a qual haveria um "esvaziamento da função 
teórica". Para ela, o conjunto de disciplinas classificadas dentro da categoria criada pelo próprio estudo, Bases Teóricas para a Infância, permitiu identificar "[...] surpreendente expansão quantitativa de disciplinas específicas de fundamentos teóricos para a educação da infância no âmbito geral." (ALBUQUERQUE, 2013, p. 163) Ou seja, no conjunto de disciplinas analisadas, a autora observa uma expansão quantitativa daquelas voltadas para os fundamentos teóricos da educação da infância, compreendendo a Educação Infantil e os anos iniciais do Ensino Fundamental.

Quanto à predominância de uma dessas etapas, ao comparar com estudo anterior (KIEHN, 2007, apud ALBUQUERQUE, 2013), a autora constata que não mais se observava a predominância do Ensino Fundamental, nos campos disciplinares que compõem o currículo dos cursos de Pedagogia.

Albuquerque (2013), além do anteriormente ressaltado, chegou a outras conclusões bem mais animadoras do que as aproximações de Gatti e Barretto (2009) e Pimenta, Fusari, Pedroso e Pinto (2017). Sua pesquisa apontou maior adequação dos currículos analisados às Diretrizes Curriculares Nacionais para a Licenciatura em Pedagogia (BRASIL, 2006), emanadas pelo Conselho Nacional de Educação (CNE). Além disso, destacou alguns aspectos que considerou positivos em relação às especificidades da primeira infância e de seus sujeitos, entre eles: a presença de diálogos interdisciplinares, assumindo como enfoque o estudo das crianças e da infância; maior preocupação com a integração entre teoria e prática e também maior atenção para as linguagens, as interações e as brincadeiras. Para essa autora, esses fatores associados revelariam uma trajetória rumo à consolidação de uma Pedagogia da Infância, mais especificamente da Educação Infantil, por meio do reconhecimento das especificidades da docência exercida em creches e pré-escolas.

Apesar dos avanços observados, a pesquisadora faz duas ressalvas importantes. A primeira a de que, em relação à pré-escola, "[...] prevalece acentralidade do processo de escolarização e da ideia de criança-aluno, na formação docente." (ALBUQUERQUE, 2013, p. 165) A segunda de que, os avanços, ainda que revelem uma situação mais bem estruturada em relação à Educação Infantil, não permitem afirmar, contudo, que já se tenha consolidado uma formação plenamente comprometida com as crianças, com a 
primeira infância e com seu direito de aprender e de se desenvolver em espaços escolares. O que a pesquisadora percebe é

[...] a existência de um movimento de reconhecimento da especificidade da docência na Educação Infantil, uma vez que se consegue evidenciar nas matrizes curriculares, especialmente no conjunto disciplinar que compõe o eixo Crianças, Infância e sua Educação, perspectivas teóricas das diversas áreas de conhecimento cuja pauta de discussão consiste no reconhecimento das crianças como sujeitos de direitos na sua mais tenra idade. (ALBUQUERQUE, 2013, p. 165)

A investigação de Albuquerque (2013), como já mencionado, incluiu apenas universidades federais, nas quais vêm se consolidando grupos de pesquisa sobre a Educação Infantil, mas que, como também assinalado acima, representam parcela pequena da oferta de cursos de Pedagogia. Esta é realizada majoritariamente, como vimos, pelas instituições privadas, nas quais, atividades de pesquisa não estão presentes, e ainda na modalidade a distância, com carga horária mínima.

\section{Pedagogia na Faculdade de Educação da UFMG: breve análise de duas matrizes curriculares}

O movimento que vem ocorrendo, nas universidades federais, em direção a um maior reconhecimento das especificidades da docência na educação infantil, percebido por Albuquerque (2013) e Albuquerque, Rocha e Buss-Simão (2018), pode ser observado ao compararmos as matrizes curriculares do curso de Pedagogia da Faculdade de Educação da Universidade Federal de Minas Gerais (FaE/UFMG), instituição na qual atuamos. A matriz que passou a vigorar a partir de 2008 foi elaborada, em substituição à proposta curricular vigente entre 2003 e 2007. Assim que o Conselho Nacional de Educação aprovou as Diretrizes Curriculares Nacionais do curso de Licenciatura em Pedagogia (2006), iniciaram-se as discussões para reforma do currículo do curso, buscando adequálo às exigências contidas no documento normativo. No primeiro semestre de 2008, iniciou-se a implantação do novo currículo.

No Quadro 1, são comparados os dois últimos currículos do Curso de Pedagogia da FaE/UFMG: o que vigorou entre 2003 e 2007 e o que passou a vigorar a partir de 2008, o qual ainda se

revista entreideias, Salvador, v. 8, n. 2, p. 157-180, maio/ago. 2019165 
encontra vigente. Observe que em ambos, o curso de Pedagogia destina-se não exclusivamente à formação para o exercício da docência na Educação Infantil, mas também nos anos iniciais do Ensino Fundamental; nos cursos de Ensino Médio, na modalidade Normal; e em cursos de Educação Profissional, na área de serviços e apoio escolar; bem como em outras áreas nas quais sejam previstos conhecimentos pedagógicos, conforme a Resolução CNE/CP n ${ }^{0} 1$, de 15 de maio de 2006. (BRASIL, 2006)

Uma primeira evidência, na comparação do currículo de 2008 ao de 2003, é, de um lado, a manutenção do número de disciplinas e, por outro lado, a redução de 60 horas no total da carga horária das disciplinas que tratavam especificamente da Educação Infantil. Entretanto, essa perda quantitativa foi compensada pela alteração que causou o maior impacto na reforma curricular: o fato de as disciplinas, cujos conteúdos tratavam especificamente de temas relacionados à Educação Infantil, passarem a ser obrigatórias para todas as alunas matriculadas no curso de Pedagogia. No currículo anterior, não era assim. Até 2008, as alunas optavam, no sétimo período do curso, por seguir uma das quatro ênfases: Educação Infantil; Educação de Jovens e Adultos; Gestão Educacional e Coordenação Pedagógica ou Alfabetização, Leitura e Escrita. Dessa forma, apesar de as egressas serem certificadas como licenciadas para atuar como professoras na Educação Infantil - e também nos anos iniciais do Ensino Fundamental -, aquelas alunas que não optassem por essa ênfase concluíam o curso sem ter tido uma discussão mais aprofundada sobre a educação e cuidado de bebês e demais crianças menores de seis anos.

Importante também acrescentar que a supressão da disciplina Fundamentos Psicológicos da Educação Infantil, causa da redução das 60 horas, deveria ser compensada pela inclusão da disciplina Estudos sobre a Infância, a ser ofertada no quarto período do curso, como disciplina obrigatória para todas as alunas. Ainda que essa nova disciplina não tratasse exclusivamente das crianças de zero a seis anos, como era o caso da anterior, e nem tampouco se restringisse aos aspectos psicológicos do desenvolvimento infantil, observando-se, pois, uma clara ampliação do escopo da disciplina para a inclusão de conteúdos relativos à Sociologia, à Antropologia e à História; a ementa, ao prever a discussão específica sobre infâncias, deveria contemplar a primeira infância, embora não de forma exclusiva. 
A oferta da disciplina Organização da Educação Infantil se manteve, porém com carga horária reduzida pela metade. Entretanto, a inclusão da disciplina Observatório do Currículo: Educação Infantil compensou essa redução, ao menos em termos quantitativos. As disciplinas Artes, Didática e Estágio mantiveram as mesmas cargas horárias tendo sofrido pequenas alterações nos títulos e nas respectivas ementas.

Finalmente, outra importante mudança foi quanto ao período de oferta das disciplinas. Antes quase exclusivamente concentradas no penúltimo semestre do curso - apenas o estágio no último semestre-,passaram a ser ofertadas, a partir de 2008, no currículo ainda vigente, de maneira um pouco mais dispersa, isso é, as cinco disciplinas encontram-se distribuídas ao longo de três períodosuma no $5^{\circ}$, três no $7^{\circ}$ e uma no $8^{\circ}$.

Quadro1-A Educação Infantil nas matrizes curriculares do curso de Pedagogia FaE/UFMG, em 2003 e em 2008

\begin{tabular}{|c|c|c|c|c|c|}
\hline \multicolumn{3}{|c|}{$\begin{array}{c}\text { Disciplinas específicas da ênfase } \\
\text { em Educação Infantil } \\
\text { Pedagogia FAE/UFMG } 2003\end{array}$} & \multicolumn{3}{|c|}{$\begin{array}{c}\text { Disciplinas diretamente relacionadas à } \\
\text { Educação Infantil } \\
\text { Pedagogia FaE/UFMG } 2008\end{array}$} \\
\hline Disciplina & Semestre & $\mathrm{CH}$ & Disciplina & Semestre & $\mathrm{CH}$ \\
\hline $\begin{array}{l}\text { Fundamentos } \\
\text { psicológicos da } \\
\text { Educação Infantil }\end{array}$ & $7^{\circ}$ & 60 & & & - \\
\hline $\begin{array}{l}\text { Organização da } \\
\text { Educação Infantil }\end{array}$ & $7^{\circ}$ & 60 & $\begin{array}{l}\text { Organização da } \\
\text { Educação Infantil }\end{array}$ & $5^{\circ}$ & 30 \\
\hline $\begin{array}{l}\text { Arte e movimento na } \\
\text { Educação Infantil }\end{array}$ & $7^{\circ}$ & 60 & $\begin{array}{l}\text { Arte na Educação } \\
\text { Infantil }\end{array}$ & $7^{\circ}$ & 60 \\
\hline $\begin{array}{l}\text { Didática: alternativas } \\
\text { da Educação Infantil }\end{array}$ & $7^{\circ}$ & 60 & $\begin{array}{l}\text { Didática na } \\
\text { Educação Infantil }\end{array}$ & $7^{\circ}$ & 60 \\
\hline $\begin{array}{l}\text { Estágio supervisionado } \\
\text { em Educação Infantil }\end{array}$ & $8^{\circ}$ & 120 & $\begin{array}{l}\text { Estágio curricular } \\
\text { na Educação } \\
\text { Infantil }\end{array}$ & $7^{\circ}$ & 120 \\
\hline & - & - & $\begin{array}{l}\text { Observatório } \\
\text { do currículo: } \\
\text { Educação Infantil }\end{array}$ & $8^{\circ}$ & 30 \\
\hline TOTAL & & 360 & TOTAL & & 300 \\
\hline
\end{tabular}

A análise do curso de Pedagogia da Faculdade de Educação da UFMG, como assinalado acima, contribui para a compreensão do movimento que se processou nos cursos de graduação em função das alterações propostas pelas Diretrizes Curriculares Nacionais do curso 
(2) Essa distribuição etária na Educação Infantil consta do documento da Base Nacional Comum Curricular, que pode ser acessado pelo link: https://goo. gl/3hV7Bs de Licenciatura em Pedagogia. (BRASIL, 2006) Entretanto, também remete aos desafios que, de certa maneira, persistiram e que precisam ser enfrentados quando se pensa em uma formação profissional capaz de assegurar, às egressas, os conhecimentos básicos para iniciarem o exercício da profissão docente na Educação Infantil.

Tendo em consideração, como vimos, que, segundo as Diretrizes Curriculares Nacionais para o Curso de Pedagogia (BRASIL, 2006), uma das licenciaturas pela qual o curso de Pedagogia certifica é a responsável pela docência na Educação Infantil, isto é, para a atuação junto aos bebês - crianças de zero a dezoito meses -; bem como junto a crianças bem pequenas - entre um ano e sete meses e três anos e onze meses -; e a crianças pequenas- de quatro anos a cinco anos e onze meses $-{ }^{2}$ seria de se imaginar que aquelas disciplinas que abordam conhecimentos relativos aos sistemas educacionais, à história da Educação, à legislação, aos fundamentos e às metodologias das diferentes áreas do conhecimento, dentre outras, tratassem também de aspectos relativos à educação da primeira infância. Entretanto, os estudos sobre os currículos do curso de Pedagogia mostram uma tendência de se privilegiar o Ensino Fundamental em detrimento da Educação Infantil. (PIMENTA; FUSARI; PEDROSO; PINTO, 2017) Resulta que todos os conhecimentos necessários para a atuação na primeira etapa da Educação Básica ficam, geralmente, circunscritos às disciplinas que levam, no título, o nome dessa etapa educativa. No caso do currículo do curso de Pedagogia da FaE/UFMG, o percentual dessas disciplinas corresponde a apenas $12 \%$ em relação ao total de disciplinas obrigatórias.

A esse desafio de incorporar as discussões sobre Educação Infantil nas demais disciplinas, acrescenta-se a extrema amplitude conferida à formação das pedagogas. Conforme artigo $2^{\circ}$, da Resolução CNE/CP n ${ }^{0} 1$, de 15 de maio de 2006 (BRASIL, 2006), além das três licenciaturas, docência na Educação Infantil, nos anos iniciais do Ensino Fundamental e nos cursos de Ensino Médio na modalidade Normal, o curso de Pedagogia certifica ainda para o exercício da docência em cursos de Educação Profissional, na área de serviços e apoio escolar, bem como em outras áreas nas quais sejam previstos conhecimentos pedagógicos.

Como se não bastasse a magnitude do número de licenciaturas, a certificação de concluintes do curso de Pedagogia não se restringe a elas. Conforme art. $4^{\circ}$ da mesma resolução, também se refere a 
atividades que compreendem participação na organização e gestão de sistemas e instituições de ensino.

Tal amplitude de atuação, conferida às concluintes dos cursos de Pedagogia, acarreta, evidentemente, grande dispersão de temas e de conteúdos a serem abordados nas disciplinas e em outras atividades acadêmicas. É de se supor que temáticas relacionadas às especificidades das infâncias e das crianças de até seis anos e de seu cuidado e educação em instituições coletivas; à elaboração de propostas e à materialização de práticas pedagógicas apropriadas a esses sujeitos; à construção de relações amistosas e colaborativas entre instituições educacionais e famílias, entre outras, dificilmente encontram espaço nas matrizes curriculares dos cursos de Pedagogia, que tantos objetivos devem cumprir.

Se isso é verdadeiro para toda a Educação Infantil, tornase ainda mais grave quando se trata da educação e cuidado das crianças com até três anos de idade, às quais se destina o segmento da creche. Tendo sido integrada ao sistema educacional há poucos anos, como parte da primeira etapa da Educação Básica e ainda não totalmente absorvida pelos sistemas de ensino, a creche e suas crianças, mormente os bebês, só agora começam a ser objeto de atenção em algumas faculdades de Educação, tanto nas pesquisas quanto na formação docente. Os grupos que se dedicam ao tema, entretanto, estão nas universidades que aliam pesquisa, ensino e extensão, quase todas públicas. E como já vimos, não são nessas instituições que se forma o maior contingente de professoras da Educação Básica.

Diante desse quadro relativo à formação inicial, resta às redes de ensino e às próprias instituições proporcionar, às profissionais em exercício, em creches e pré-escolas, oportunidades de formação continuada. Isso requer recursos financeiros, nem sempre disponíveis, e dedicação significativa de tempo das professoras, também restrito nesses sistemas e instituições. A formação continuada é uma necessidade do desenvolvimento profissional, e não é dispensável, mesmo quando se conta com boa formação inicial. Porém, se tornará mais exigente e dispendiosa quando essa não tiver cumprido seu papel.

\section{A formação docente e a constituição de uma Educação Infantil de qualidade}


$\mathrm{Na}$ expectativa de contribuir com o debate e considerando as reflexões advindas da análise das matrizes curriculares, destacamos a seguir alguns aspectos que consideramos essenciais de serem observados nas propostas de formação de professoras da Educação Infantil.

Um primeiro aspecto consiste em assegurar conhecimentos psicológicos, sociológicos, antropológicos que contribuam para se compreender as crianças e as formas como elas interagem com o mundo. Conhecer como as crianças aprendem, que perguntas elas se fazem, como se situam no mundo; que fatores sociais, culturais, políticos, financeiros cruzam suas vidas, influenciando-as e sendo influenciadas pelas categorias classe social, gênero, etnia etc.

Um segundo aspecto refere-se à garantia de conhecimentos pedagógicos, que ajudem as professoras a planejarem, organizarem, desenvolverem uma trajetória educativa capaz de ampliar as experiências das crianças em relação "[...] às dimensões expressivomotora, afetiva, cognitiva, linguística, ética, estética e sociocultural da criança". (BRASIL, 2009)

Em terceiro lugar, respeitar e considerar, nos processos formativos, a riqueza da diversidade brasileira. Nas propostas curriculares dos cursos de formação, precisam ser contempladas as marcas, as manifestações culturais e as formas de cuidar das crianças, e de educá-las, que caracterizam as diferentes sociedades, comunidades e grupos sociais. Promover o conhecimento e o respeito às diversidades culturais, regionais e locais, é uma forma de superar a estereotipia presente nas práticas pedagógicas, aspecto a ser forte e urgentemente suplantado na formação a que as docentes da Educação Infantil vêm sendo submetidas.

Em quarto lugar, a proposta curricular deve estar ancorada em uma concepção de formação docente contra-hegemônica, no sentido de opor-se à racionalidade técnica. É necessário reconhecer que a atividade profissional exercida pelas professoras não é meramente a de solucionar problemas definidos a priori, por pesquisadores, por editoras de livros didáticos, por instituições responsáveis pela formação ou por gestores educacionais. Nem tampouco se trata da mera aplicação de técnicas, também elas concebidas e impostas por esses mesmos agentes. A capacidade de problematizar a realidade, que depende do quadro de referência político e filosófico de cada professora, é um aspecto a ser desenvolvido na formação profissional. Enfim, significa pensar a professora como agente de 
construção da própria prática; que inclui, de um lado, a capacidade de definir que problemas devem ser levados em conta e, de outro lado, a busca autônoma de caminhos para superá-los.

$\mathrm{E}$, finalmente, estabelecer uma relação profunda, consistente e constante entre teoria e prática. A literatura é bastante extensa sobre o assunto. Autores como Schon (1997, 2000, 2018) e Nóvoa (1992a, 1992b, 1992c) vêm sistematicamente insistindo que a superação desse problema passa pela formação dos professores como profissionais reflexivos, o que, para esses teóricos, pressupõe tomar as instituições educativas como espaços de formação e seus professores como protagonistas do próprio processo de formação profissional. Ainda na formação inicial, é possível e necessário que a reflexão sobre o fazer docente, sobre as práticas educativas seja elemento central para a aquisição de conhecimentos e saberes básicos para o exercício da função de educar e cuidar na Educação Infantil.

\section{Proposta de formação inicial: um convite ao debate}

Como esperamos ter evidenciado, o curso de Pedagogia da FaE/ UFMG, assim como os das demais Instituições Federais de Ensino, não oferecem uma formação inicial específica para a docência na Educação Infantil. Ainda que constatemos, no caso do curso em tela, o aumento de conteúdos e de disciplinas dedicadas à formação dessas profissionais, sobretudo após a aprovação das Diretrizes Curriculares Nacionais para os cursos de Pedagogia (BRASIL, 2006), os desafios da ação docente parecem requerer uma formação específica, capaz de integrar conteúdos e disciplinas ao longo da trajetória acadêmica das futuras professoras da primeira infância.

À guisa de provocação, apresentamos a seguir uma proposta de formação inicial para a docência na Educação Infantil. Trata-se de um exercício que deve ser compreendido como uma oportunidade de contribuir com o sonho de alçar essa etapa da Educação Básica ao lugar compatível com a dignidade da infância e das crianças. (CURY, 1998)

No desenvolvimento do curso, para garantir os princípios aqui enunciados poder-se-ia observar as seguintes diretrizes:

1. Os estágios curriculares obrigatórios seriam concebidos como tempos de imersão nas escolas e ocorreriam em um período de um ou dois meses consecutivos, durante os quais não haveria

revista entreideias, Salvador, v. 8, n. 2, p. 157-180, maio/ago. 2019171 
aulas ou outras atividades acadêmicas, exceto aquelas próprias à orientação do estágio.

2. Os estágios seriam realizados em instituições educativas cadastradas, a partir de critérios pré-estabelecidos pela Instituição de Ensino Superior. Os profissionais das instituições de Educação Infantil, responsáveis por acompanhar as alunas no campo de estágio, fariam reuniões sistemáticas, ao longo do processo, juntamente com a equipe de professoras da Faculdade, responsáveis pela orientação das estagiárias, com o objetivo de construírem coletivamente estratégias de acompanhamento e avaliação da prática de estágio.

3. As disciplinas consideradas teóricas teriam uma carga horária dedicada à prática, por meio de observações, atividades desenvolvidas em instituições educativas ou discussões em sala de aula que tomassem a prática cotidiana como objeto de reflexão.

4. O Trabalho de Conclusão de Curso (TCC) consistiria em um texto contendo a descrição e a análise crítica das experiências dos quatro estágios realizados ao longo do curso, com a necessária fundamentação teórica apreendida em todas as disciplinas.

5. A construção do TCC teria início já no primeiro semestre, como resultado do relatório elaborado para a primeira disciplina de estágio (Conforme Quadro 2, Estágio curricular I: conhecendo as instituições de Educação Infantil).

6. As disciplinas Metodologia de pesquisa seriam espaços de reflexão sobre a experiência de estágio, integrando teoria e prática, bem como de orientação para a escrita do TCC.

7. Ao longo dos quatro anos de curso, as alunas iriam construindo seu projeto de intervenção. O relatório final seria o seu TCC, que trataria da experiência, desde o primeiro até o último estágio. O texto final seria a problematização da experiência resultante da observação e da proposição de situações de aprendizagem, à luz das teorias estudadas.

8. A orientação do estágio seria realizada por uma equipe permanente, interdisciplinar e interdepartamental de professores da Faculdade, com experiência na formação de professoras da Educação Infantil e em pesquisas sobre essa etapa educativa. 
9. As atividades didáticas, "Oficina: o professor como agente de cultura I, II, III e IV" (conforme Quadro 2), presentes em quatro semestres, tratariam de aspectos relacionados a diversas manifestações culturais, contemplando visitas a museus, bibliotecas, cinemas, teatros, espetáculos de dança, de grupos folclóricos, experiências literárias, de gastronomia etc. A equipe responsável pela organização dessas oficinas também seria multidisciplinar e integrada por professores de todos os departamentos, com ampla experiência em Educação Infantil.

10. As atividades didáticas, "Seminários temáticos I, II e III" (conforme Quadro 2), tratariam de temas relacionados à área da Educação Infantil que, por seu caráter embrionário, não estariam contemplados nas demais disciplinas acadêmicas. A equipe responsável pela organização desses seminários também seria multidisciplinar e oriunda dos diferentes departamentos.

11. Os conteúdos, que tradicionalmente são trabalhados nas disciplinas de fundamentos da Educação, tais como Sociologia, História, Filosofia, Política, Psicologia seriam tratados nas disciplinas como temas basilares, de maneira inter e transdisciplinar e em função daquilo que se considera essencial ao exercício da profissão docente junto a bebês e demais crianças pequenas.

12. Os conteúdos relacionados à linguagem musical, à dança, à linguagem corporal, ao teatro, às artes visuais seriam trabalhados em formato de oficinas, tentando romper com a lógica disciplinar e dando maior ênfase à experimentação das próprias alunas e aos elementos necessários à formação para atuar junto às crianças.

13. As disciplinas optativas teriam eixos pré-estabelecidos a serem definidos pelo colegiado do curso, considerando as demandas dos respectivos contextos político, econômico, social.

Reiteramos o caráter de provocação para o debate que nos inspirou a apresentar esta proposta. Ao elaborarmos essas diretrizes, tentamos responder a questões e a desafios impostos pelo exercício da profissão docente junto a crianças nos seus primeiros anos de vida, tendo como base as Diretrizes Curriculares Nacionais para a Educação Infantil. (BRASIL, 2009)

Com duração de oito períodos, o curso se estruturaria nas seguintes disciplinas e atividades acadêmicas apresentadas no Quadro 2 a seguir.

revista entreideias, Salvador, v. 8, n. 2, p. 157-180, maio/ago. 2019173 
Quadro 2 - Proposta de matriz curricular para curso de licenciatura para Educação Infantil

\begin{tabular}{|c|c|}
\hline PERÍODO & DISCIPLINAS \\
\hline $1^{\circ}$ & $\begin{array}{l}\text { 1. Aprendizagem e desenvolvimento infantil I } \\
\text { 2. O brincar como eixo das práticas educativas } \\
\text { 3. Oficina I: o professor como agente de cultura } \\
\text { 4. Metodologia I - pesquisa na Educação Infantil: iniciação ao } \\
\text { trabalho de conclusão de curso - TCC } \\
\text { 5. Estágio curricular I: conhecendo as instituições de Educação } \\
\text { Infantil }\end{array}$ \\
\hline $2^{\circ}$ & $\begin{array}{l}\text { 1. Seminário temático I } \\
\text { 2. Cuidado pessoal, saúde, auto-organização e bem-estar das } \\
\text { crianças na Educação Infantil } \\
\text { 3. Oficina: música na Educação Infantil } \\
\text { 4. Práticas educativas na Educação Infantil I: os bebês e as crianças } \\
\text { pequenas como sujeitos de linguagem } \\
\text { 5. História da Educação Infantil e teorias pedagógicas }\end{array}$ \\
\hline $3^{\circ}$ & $\begin{array}{l}\text { 1. Aprendizagem e desenvolvimento humano II } \\
\text { 2. Políticas públicas, intersetorialidade e relações com as famílias } \\
\text { 3. Práticas educativas na Educação Infantil II: crianças pequenas } \\
\text { como sujeitos de linguagem } \\
\text { 4. Metodologia II - pesquisa na Educação Infantil: elaborando o TCC } \\
\text { 5. A inclusão de bebês e demais crianças pequenas com deficiência } \\
\text { e a atuação do docente da Educação Infantil } \\
\text { 6. Avaliação de contexto na Educação Infantil }\end{array}$ \\
\hline $4^{\circ}$ & $\begin{array}{l}\text { 1. Aprendizagem e desenvolvimento humano III } \\
\text { 2. Práticas educativas na Educação Infantil III: bebês, crianças bem } \\
\text { pequenas e as relações quantitativas, as medidas, as formas e as } \\
\text { relações espaço-temporais } \\
\text { 3. Oficina II: o professor como agente de cultura } \\
\text { 4. Oficina: as artes visuais e a Educação Infantil } \\
\text { 5. Seminário temático II } \\
\text { 6. Estágio curricular II: observando e propondo práticas educativas } \\
\text { junto a bebês e crianças bem pequenas }\end{array}$ \\
\hline $5^{\circ}$ & $\begin{array}{l}\text { 1. Práticas educativas na Educação Infantil IV: crianças pequenas } \\
\text { e as relações quantitativas, as medidas, as formas e as relações } \\
\text { espaço-temporais } \\
\text { 2. Libras para professoras da primeira infância } \\
\text { 3. Oficina: corpo, dança e movimento na Educação Infantil } \\
\text { 4. Oficina III: o professor como agente de cultura } \\
\text { 5. Literatura infantil e a educação literária de bebês e demais crianças } \\
\text { pequenas } \\
\text { 6. Optativas }\end{array}$ \\
\hline
\end{tabular}




\begin{tabular}{|l|l|}
\hline \multirow{2}{*}{$6^{\circ}$} & $\begin{array}{l}\text { 1. Práticas educativas na Educação Infantil V: bebês, demais crianças } \\
\text { bem pequenas e o mundo físico, natural e social } \\
\text { 2. Avaliação, projetos e documentação pedagógica na Educação } \\
\text { Infantil } \\
\text { 3. Carreira e trabalho docente na Educação Infantil } \\
\text { 4. Metodologia III - pesquisa na Educação Infantil: concluindo o TCC } \\
\text { 5. Currículo, projeto pedagógico e campos de experiência na } \\
\text { Educação Infantil } \\
\text { 6. Estágio curricular III: observando e propondo práticas educativas } \\
\text { com crianças pequenas }\end{array}$ \\
\hline $7^{\circ}$ & $\begin{array}{l}\text { 1. Práticas educativas na Educação Infantil VI: as crianças pequenas } \\
\text { e o mundo físico, natural e social } \\
\text { 2. Gestão e coordenação pedagógica na educação infantil } \\
\text { 3. Oficina IV: o professor como agente de cultura } \\
\text { 4. Estágio curricular IV: observando e propondo práticas educativas } \\
\text { junto a crianças pequenas } \\
\text { 5. Seminário temático III }\end{array}$ \\
\hline $8^{\circ}$ & $\begin{array}{l}\text { 1. Metodologia IV - pesquisa na Educação Infantil: finalizando e } \\
\text { apresentando o TCC } \\
\text { 2. Culturas brasileiras e diversidade } \\
\text { coordenação pedagógica na Educação Infantil } \\
\text { 4. Optativas }\end{array}$ \\
\hline
\end{tabular}

Fonte: elaboração das autoras.

\section{Considerações finais}

A formação de docentes das diferentes etapas e modalidades da Educação Básica, pautada nos direitos de todos e de cada um à Educação, exige que sejam consideradas as especificidades dos ciclos de vida, da história que os constituiu como categorias socioculturais próprias, da natureza das experiências e vivências dos sujeitos das diversas idades, e do lugar que os ciclos de vida humanos ocupam no sistema educacional, entre outras particularidades.

Buscamos, neste artigo, trazer à reflexão aspectos que consideramos essenciais quando se discute a docência na Educação Infantil, destinada às crianças pequenas, inclusive aos bebês, levando-se em conta suas especificidades. A docência na Educação Infantil requer conhecimentos psicológicos, sociológicos, antropológicos, históricos, culturais, políticos e pedagógicos que possibilitem: compreender esses sujeitos complexos e concretos que vivem sua infância também em ambientes coletivos educacionais; 
entender fatores sociais, políticos, econômicos e culturais que se entrecruzam na constituição e nas ações desses sujeitos em suas relações com o mundo; saber como planejar, organizar os tempos e espaços e desenvolver ações capazes de ampliar as experiências das crianças em relação às diferentes dimensões contempladas nas Diretrizes Curriculares Nacionais para a Educação Infantil; conhecer, respeitar e considerar as diferenças culturais, regionais e locais que constituem a diversidade brasileira. Todos esses conhecimentos devem ser desenvolvidos na formação, por meio de uma relação profunda, consistente e constante entre teoria e prática. Na proposta de matriz curricular para a formação inicial para docência na Educação Infantil apresentada, procuramos contemplar esses conhecimentos e saberes.

Não há dúvidas de que deficiências observadas na formação inicial comprometem a qualidade da Educação Infantil oferecida às crianças e fazem recair sobre a formação continuada o ônus de suprir essas deficiências e ausências dos cursos de habilitação prévia. Da formação continuada, que muitas vezes reproduz os problemas da formação inicial, espera-se que cumpra o papel de aprofundar e atualizar conhecimentos teóricos e práticos e promover o desenvolvimento permanente do profissional. Vale destacar que a oferta de formação inicial e continuada numa mesma instituição formadora, como tem ocorrido em várias de nossas universidades públicas, constitui oportunidade de articulação e diálogo, de modo que as experiências de uma beneficiam a outra. Por seu lado, a instituição de Educação Infantil constitui um lócus privilegiado de desenvolvimento de seus profissionais, quando as experiências docentes são objeto de reflexão coletiva. Não é preciso, entretanto, esperar o ingresso das profissionais nas instituições para que as práticas educativas, que nelas ocorrem, cotidianamente, sejam objetos de reflexão e análise das futuras docentes.

Ressaltamos também que os processos envolvidos na formação são mais profundos e complexos do que a aquisição de habilidades e de competências técnicas. Os professores se tornam os professores que são porque retraduzem para si, a partir das suas características pessoais, os conhecimentos teóricos, as interações que vivenciam dentro e fora da escola, as observações que fazem de outras práticas docentes antes de se tornarem professores e, depois, no próprio contexto onde atuarão. Vale lembrar que "[...] o professor é uma pessoa e parte importante da pessoa é o professor." (NIAS, 1991 
apud NÓVOA, 1992a, p. 25) Daí a relevância de a história de vida estar presente na configuração da carreira docente, que começa na formação inicial e, algumas vezes, até mesmo antes dela.

É igualmente importante que a reflexão, sobre essas várias histórias, perpasse os processos de formação, desde a graduação, e continue ao longo de toda a carreira profissional. Para tanto, as disciplinas que compõem as matrizes curriculares dos cursos de licenciatura em Pedagogia precisam garantir espaços de reflexão e de vivências de práticas culturais e pedagógicas, que ajudem as futuras professoras a se conhecerem, a se perceberem como sujeitos históricos e agentes de cultura. E que sejam capazes de perceber as crianças como sujeitos de direitos e, sobretudo, de se sensibilizarem com o que elas nos revelam. Como nos ensinou Hannah Arendt (2002), enxergar nas crianças a capacidade que o mundo tem de se renovar a cada dia, por meio do nascimento e da espontaneidade desses que acabaram de chegar.

\section{Reflections on the training of teachers of and for early childhood education}

\begin{abstract}
This article aims to analyse the training of teachers in early childhood education, using statistics on the education of these professionals, characteristics of the courses which they take and results of recent studies on the place of early childhood education in curriculum matrices of Pedagogy courses, in which these professionals must be trained, in accordance with the National Curricular Guidelines for Pedagogy Courses. Attention is also drawn to factors, which, in the view of the authors, are essential in the training of teachers, for the quality of the childhood education offered in the Country. Considering the problems identified by several authors on the dispersion of the object of the Pedagogy course, defined in the resolution of 2006, which renders the offered training fragmented and superficial, a proposal for a curricular matrix for undergraduate education was proposed as a provocation for debate. The matrix was built with the intention of training early childhood education teachers, trained to care for and educate children in nursery schools and kindergartens, according to the National Curriculum Guidelines for Early Childhood Education.
\end{abstract}

Keywords: Training of teachers. Pedagogy Course. Curriculum. Early Childhood Education.

\section{Reflexiones sobre la formación de docentes de y para la educación infantil}

Resumen: En este artículo, se intenta analizar la formación de las profesoras ${ }^{3}$ de Educación Infantil, utilizando estadísticas sobre escolaridad de dichas profesionales, características de los cursos que las forman y resultados de estudios recientes sobre el lugar de la Educación Infantil en las matrices
(3) "Al referirnos a las profesionales que ejercen la docencia en la educación infantil, utilizaremos el género femenino, considerando el hecho de que esta profesión es ejercida, em su gran mayoría por mujeres. Aunque somos conscientes de que hay hombres que desempeñan esta profesión y esperamos que esa participación aumente, lo que sindu da ofrecerá los beneficios que proporciona la diversidad. De la misma manera, utilizaremos el género feminino al referirnos al seguimiento de estudiantes de Pedagogía, com las mismas reservas presentadas em relación a las profesionales." 
curriculares de cursos de Pedagogía, em los cuales deben ser formadas esas profesionales en consonancia con las Directrices Curriculares Nacionales para el Curso de Pedagogía. También se señalan aspectos que, desde el punto de vista de las autoras, son esenciales em la formación de profesoras, para la calidad de la Educación Infantil ofrecida en el país. Considerando los problemas identificados por vario(a)s autore(a)s sobre la dispersión del objeto del curso de Pedagogía, definido en la resolución de 2006, que hace que la formación ofrecida sea fragmentada y superficial, se presenta una propuesta de matriz curricular para la licenciatura en Educación Infantil, como incitación al debate. La matriz se construyó teniendo como objetivo la formación de las profesoras de educación infantil, capacitadas para cuidar y educar a niños en guarderías y centros preescolares, según las Directrices Curriculares Nacionales para la Educación Infantil.

Palabras clave: Formación de maestros. Carrera de Pedagogía. Plan de estudios. Educación Infantil.

\section{Referências:}

ALBUQUERQUE, M. H. de. Formação Docente para Educação Infantil no Brasil: Configurações Curriculares nos Cursos de Pedagogia.2013.198 f. Tese (Doutorado em Educação) - Faculdade de Educação, Universidade Federal de Santa Catarina. Florianópolis, 2013.

ALBUQUERQUE, M. H. de; ROCHA, E. C.; BUSS-SIMÃO, M. Formação Docente para Educação Infantil nos currículos da Pedagogia. 2013. Educação em Revista, Belo Horizonte, v. 34,2018.

ARENDT, H. O que é política. Rio de Janeiro: Bertrand Brasil, 2002.

BARRETTO, E. S. Políticas de formação docente para a educação básica no Brasil: embates contemporâneos. Revista Brasileira de Educação, Rio de Janeiro, v. 20, n. 62, jul./set. 2015.

BRASIL. Lei n. 9.394, de 20 de dezembro de 1996. Estabelece as diretrizes e bases da educação nacional. Diário Oficial da União, Brasília, DF, 23 dez. 1996.

BRASIL. Ministério da Educação. Conselho Nacional de Educação. Resolução CNE/CP 1/2006. Institui as Diretrizes Curriculares Nacionais par o Curso de Graduação em Pedagogia. Diário Oficial da União, Seção 1, p. 11. Brasília, DF, 16 maio 2006.

BRASIL. Ministério da Educação. Conselho Nacional de Educação. Resolução CNE/CEB 5/2009. Fixa as Diretrizes Curriculares Nacionais para a Educação Infantil. Diário Oficial da União, Seção 1, p.18. Brasília, DF, 18 dez. 2009.

BRASIL. Ministério da Educação. Instituto Nacional de Estudos e Pesquisas Educacionais Anísio Teixeira. Censo Escolar, 2008. Brasília, DF, 2008.

BRASIL. Ministério da Educação. Instituto Nacional de Estudos e Pesquisas Educacionais Anísio Teixeira. Censo Escolar, 2017. Brasília, DF, 2017a. 
BRASIL. Ministério da Educação. Instituto Nacional de Estudos e Pesquisas Educacionais Anísio Teixeira. Sinopse Estatística da Educação Superior, 2017. Brasília, DF, 2017b.

BRASIL. Lei n. 12.796, de 4 de abril de 2013. Altera a lei n. 9.394, de 20 de dezembro de 1996, que estabelece as diretrizes e bases da educação nacional, para dispor sobre a formação dos profissionais da educação e dar outras providências. Diário Oficial da União, Brasília, DF, 5 abr. 2013.

BRASIL. Lei n. 13.415, de 16 de fevereiro de 2017. Altera a lei n. 9.394, de 20 de dezembro de 1996, que estabelece as diretrizes e bases da educação nacional. Diário Oficial da União, Brasília, DF, 17 abr. 2017c.

CURY, C. R. J. A educação infantil como direito. Subsídios para credenciamento e funcionamento de instituições de educação infantil. Brasília, DF: MEC/SEF/DPE/COEDI, 1998.

GATTI, B. A. Formação de Professores no Brasil: características e problemas. Educação e Sociedade. Campinas, v. 31, n. 113, p. 1355-1379, out./dez. 2010.

GATTI, B. A.; BARRETTO, E. S. S. Professores do Brasil: impasses e desafios. Brasília, DF: Unesco, 2009.

NÓVOA, A. Formação de professores e formação docente. In: NÓVOA, A. Os professores e a sua formação. Lisboa: Dom Quixote, 1992a.

NÓVOA, A. Para uma análise das instituições escolares. In: NÓVOA, A. As organizações escolares em análise. Lisboa: Dom Quixote, 1992b.

NÓVOA, A. Os professores e as histórias da sua vida. In: NÓVOA, A. Vidas de professores. Porto: Editora Porto, 1992c.

PIMENTA, S.G.; FUSARI. J.C.; PEDROSO. C. C. A.; PINTO, U. A. Os cursos de licenciatura em pedagogia: fragilidades na formação inicial do professor polivalente. Educação e Pesquisa. São Paulo, v. 43, n. 1, p. 15-30, jan./mar. 2017.

SCHÖN, D. Educating the reflective practitioner; Donald Schön's presentation to the 1987 meeting of the American Educational Research Association. Washington, DC, 1987. Disponível em:http://post.queensu. $\mathrm{ca} /$ russellt/howteach/schon87.htm. Acesso em: 11 out. 2018.

SCHÖN, D. Formar professores como profissionais reflexivos. In: NÓVOA, A. (org.). Os professores e a sua formação. 3. ed. Lisboa: Dom Quixote, 1997. p. 79-91.

SCHÖN, D. Educando o profissional reflexivo: um novo design para o ensino e a aprendizagem. Porto Alegre: Artes Médicas, 2000.

SCHEIBE, L. Formação de professores; dilemas da formação inicial a distância. Educere et Educare. Cascavel: v. 1, n. 2, p. 199-212, jul./dez. 2006.

Submetido: 20/11/2018

Aceito: 22/05/2019

revista entreideias, Salvador, v. 8, n. 2, p. 157-180, maio/ago. 2019179 
